\title{
Recent progresses in the phenomenological description for the indentation size effect in microhardness testing of brittle ceramics
}

\author{
Danyu JIANG * \\ State Key Laboratory of High Performance Ceramics and Superfine Microstructure, \\ Shanghai Institute of Ceramics, Shanghai 200050, China \\ Received October 10, 2011; Accepted November 15, 2011 \\ (C) The Author(s) 2012. This article is published with open access at Springerlink.com
}

\begin{abstract}
The indentation hardness of a given material is usually load-dependent and such a phenomenon is generally referred to as the indentation size effect (ISE). The existence of ISE means that, if hardness is used as a material selection criterion, it is clearly insufficient to quote a single hardness number. Several empirical or semi-empirical equations, including the Meyer's law, the Hays-Kendall approach, the energy-balance approach, the proportional specimen resistance (PSR) model and the modified PSR model, etc., have been proposed for the description of the variation of the indentation size with the applied test load and for determining the so-called load-independent hardness. This paper reviews these existing empirical equations, with a special emphasis on the analysis and the application of the modified PSR model.
\end{abstract}

Key words: indentation; hardness; size effect; residual stress

\section{Introduction}

Low-load indentation hardness testing is a convenient means of investigating the mechanical properties of a small volume of solid materials. The conventional procedure of hardness testing consists of applying a fixed load on a diamond indenter and measuring, with the help of an optical microscope, the dimensions of the resultant indentation impression on the surface of the test material after unloading. Then the hardness number, $H$, can be calculated as the ratio of the applied load, $P$, to the contact or projected area, $A$, of the resultant indentation impression, i.e.,

\footnotetext{
* Corresponding author.

E-mail: dyjiang@mail.sic.ac.cn
}

$$
H=\frac{P}{A}=k \frac{P}{d^{2}}
$$

where $d$ is the measured length of indentation diagonal and $k$ is a constant equal to 1.8555 for Vickers hardness testing and 14.229 for Knoop hardness testing.

It has been well-known for a long time [1-10] that the hardness number calculated with Eq. (1) is usually load-dependent. Figure 1 shows the load-dependences of the measured hardness for some brittle ceramics. As can be seen, although there are slight scatters in the experimental data, a graduate decreasing tendency in the measured hardness with increasing load can be observed for each material examined. Such a phenomenon is frequently referred to as the indentation size effect (ISE). The existence of the ISE implies that, 


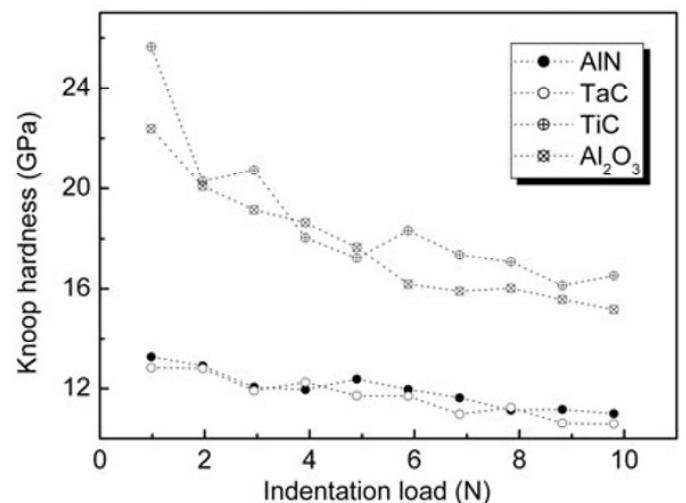

Fig. 1 Load-dependence of Knoop hardness of some ceramic materials. Data from Ref. [11]

if hardness is used as a materials selection criterion, it is clearly insufficient to quote a single hardness number, since using a load-dependent hardness number in material characterization may result in some unreliable conclusions.

The origin of the ISE has been studied extensively for about one century [12-14] but now is still a controversial subject. Several possible theoretical explanations have been proposed. The most common explanations found in the literature are experimental errors resulting from the limitations of the resolution of the objective lens [15] and the sensitivity of the load cell [16]. The second set, which is described by Bückle [17] as the apparent causes of errors, is directly related to the intrinsic structural factors of the test materials, including indentation elastic recovery [18], work hardening during indentation [12], surface dislocation pining [19], etc. During the past two decades, several new theoretical models have also been proposed [20-22]. However, recent reviews [9,10] have shown that, despite much interest, the cause of the ISE has never been satisfactorily achieved.

On the other hand, the origin of the ISE was also explored phenomenologically by many authors [23-27], who tried to make critical comparisons between the applicabilities and efficacies of different empirical or semi-empirical equations in describing the experimentally measured indentation data. The frequently employed empirical or semi-empirical equations for describing the variation of the indentation size with the applied test load include the Meyer's law [28], the Hays-Kendall approach [29], the elastic recovery model [18], the energy-balance approach [30], the proportional specimen resistance (PSR) model [4], etc. Based on the analyses of a mass of experimental data, a modified PSR model was proposed [6] in 1999 to describe the observed ISE and to determine the load-independent hardness number. The physical meanings of the modified PSR model were also discussed in detail. Then, this new model was employed to analyze the hardness characteristics of a series of brittle materials, including glasses [31], ceramics (both dense [32,33] and porous [34]), cermets [35] and ceramic-matrix composites [36,37]. It was well proved that the modified PSR model can give a satisfactory description of the measured indentation data and a reasonable explanation for the observed ISEs can be provided based on this model. Recently, the applicability of the modified PSR model in analyzing the indentation size effect observed in nanoindentation tests was also examined by several authors [38,39]. Furthermore, this model was also found [40] to be suitable for describing the so-called reversed indentation size effect (RISE), i.e., an increasing tendency in the measured hardness with increasing load.

The purpose of this paper is to give a brief review on the existing phenomenological models for describing the ISE in hardness testing, with a special emphasis on the analysis and the application of the modified PSR model. The aims of this paper are to show how to give a satisfactory description for the experimentally measured data and then to yield a so-called true hardness number. Therefore, models based mainly on theoretical analysis will be not concerned in this paper.

\section{Existing models}

\subsection{Meyer's law}

A traditional way to analyze the indentation size effect in hardness testing is to fit the experimental data according to the classical Meyer's law, which correlates the applied load, $P$, and the resulting indentation size, $d$, with [28]

$$
P=\beta d^{n}
$$

where $\beta$ and $n$ are descriptive parameters derived from the curve fitting of the experimental data.

Compared with Eq. (1), we can find that the ISE can be related to the derivation of the $n$-value from 2 and material with a $n$-value equal to two would not exhibit ISE. 
Meyer's law has been well-proven suitable for the representation of the experimental data for a variety of materials including brittle ceramics and, in general, the Meyer exponent $n$ has been experimentally observed to be between 1.5 and 2.2 [1,6,41,42]. Combining Eqs. (1) and (2) gives,

$$
H=k \beta d^{n-2}
$$

Equation (3) shows that, for the case of $n>2$, a reversed indentation size effect would be observed.

Several authors have tried to ascertain some possible microstructural effects on the Meyer's parameters. For example, Sargent and Page [43] found that, for polycrystalline ceramics, lower $n$ values are generally associated with higher $\ln \beta$ values as the grain size increases. In a study on the Vickers hardness testing for hot-pressing $\mathrm{Si}_{3} \mathrm{~N}_{4}$-based ceramics, Babini et al. [41] also found that, as grain size increases, the $n$ value increases while the $\beta$ value decreases. The degree of the correlation between $n$ and $\beta$ was verified to be more evident for single crystals. By analyzing the Knoop indentation data measured on different crystallographic planes and for different crystallographic directions in two rutile-structure single crystals, $\mathrm{TiO}_{2}$ and $\mathrm{SnO}_{2}, \mathrm{Li}$ and Bradt [4] obtained an inverse linear relationship between $n$ and $\beta$ and this line extrapolates to $n=2$ at $\beta=0$ which was considered by Li and Bradt [44] to substantiate that Mayer's law is only applicable when an indentation size effect exists.

When using the relationship between $\beta$ and $n$ to discuss the microstructural effects or other material behavior, however, one should be aware of the fact that the best-fit value of the parameter $\beta$ is strongly dependent on the unit system used for recording the indentation parameters, $P$ and $d$. The use of different unit systems would result in different trends of the variation of $\beta$ with $n$. As an example, Fig. 2 shows the results reported by Gong et al. [36] for a series of $\mathrm{Al}_{2} \mathrm{O}_{3}$-TiC composite samples. The average sizes of the TiC particles used for preparing the composites were different from sample to sample, making the hardness of the samples increases with the TiC particle size [36]. Meyer's law was found to be satisfactorily suitable for describing the indentation data for each sample. As shown in Fig. 2, however, completely different trends are observed when different unit systems were used, respectively, to record the experimental data. When recording $P$ in Newton $(\mathrm{N})$

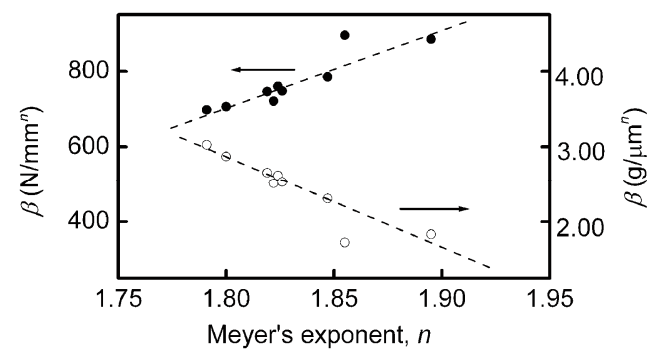

Fig. 2 Variation of Meyer's law coefficient $\beta$ with Meyer's exponent $n$ for $\mathrm{Al}_{2} \mathrm{O}_{3}$-TiC composites. Note that completely different trends are observed when different unit systems were used to record the indentation data. Data from [36], Knoop indentation

and $d$ in millimeter $(\mathrm{mm})$, it yields an increasing tendency in $\beta$ with increasing $n$. When recording $P$ in gram $(\mathrm{g})$ and $d$ in micrometer $(\mu \mathrm{m})$, however, $\beta$ was determined as a decreasing function of $n$.

In summary, a satisfactory explanation of the physical meanings of the parameters $n$ and $\beta$ included in Eq. (2) is still lacking and, in analyzing the indentation data, Meyer's law may be used only as an empirical equation. Because its simplicity, Meyer's law is still a mostly adopted method for studying the load-dependence of the measured hardness. At least, the Meyer's exponent, $n$, may be used in some cases as an index for comparing the load-sensitivity of the measured hardness between different materials.

\subsection{Energy-balance consideration}

The energy-balance consideration was originally proposed by Frohlich et al. [30]. The basic assumption in the energy-balance consideration is that, during an indentation process, the external work applied by the indenter is converted into a strain energy component, proportional to the volume of the resultant impression, and a surface energy component, proportional to the area of the resultant impression. This assumption results in the following general formula to relate the indentation size, $d$, with the applied load, $P$,

$$
P d=\alpha_{1} d+\alpha_{2} d^{2}
$$

where $\alpha_{1}$ and $\alpha_{2}$ are constants.

According to the analysis of Frohlich et al. [30], the first term of the right side of Eq. (4) represents the surface energy contribution while the second term represents the volume energy contribution. Following this idea, Gong and Guan [45] deduced Eq. (4) based on the elastic/plastic indentation model developed by 
Lawn et al. [46], and attributed some explicit physical meanings to the parameters $\alpha_{1}$ and $\alpha_{2}$. In general, all the possible mechanisms that may result in a change in the area of free surface in the material may contribute to the parameter $a_{1}$.

According to Eq. (4), the total load, $P$, is now separated into two parts, and only the second term of the right side of Eq. (4) is related to the permanent deformation caused by indentation. Thus a load-independent hardness, sometimes referred to as the true hardness, $H_{\mathrm{T}}$, can be defined as $[1,30]$ :

$$
H_{\mathrm{T}}=\frac{P-\alpha_{1} d}{A}=k\left(\frac{\alpha_{2} d^{2}}{d^{2}}\right)=k \alpha_{2}
$$

Equation (5) shows that the constant $\alpha_{2}$ in Eq. (4) is in fact a measure of the so-called true hardness.

To determine the true hardness number, $H_{\mathrm{T}}$, with Eq. (5), the value of the parameter $\alpha_{2}$ should be known first. So Eq. (4) is usually transformed into:

$$
\frac{P}{d}=\alpha_{1}+\alpha_{2} d
$$

It can be expected from Eq. (6) that a plot of $P / d$ vs $d$ would yield a straight line and $\alpha_{2}$ can be readily evaluated through the linear regression.

Clearly, the applicability of the energy-balance consideration can be examined by testing the linearity between $P / d$ and $d$. The energy-balance consideration has been employed by many authors $[1,2,47-50]$ to analyze the indentation size effect observed in different materials and a good linear relationship between $P / d$ and $d$ was generally observed within a certain range of the applied indentation load. For example, Fig. 3 shows the plots of $P / d$ versus $d$ for several typical materials using the data reported by Young and Rhee [11] and a linear relationship between $P / d$ and $d$ is clearly evident for each materials, see the solid lines in Fig. 3.

The main advantage of the energy-balance model compared with the Meyer's law is that the physical meanings of the parameters used in the former are explicit. However, the energy-balance model also has some shortcomings. When examining Fig. 3 carefully, one can find that, in some cases, it seems to be more suitable to describe the experimental data with two, rather than one, straight lines, see the dashed lines in Fig. 3. In other words, the basic equation for energy-balance model, Eq. (4), seems to be valid only within a very narrow load range. Gong et al. analyzed

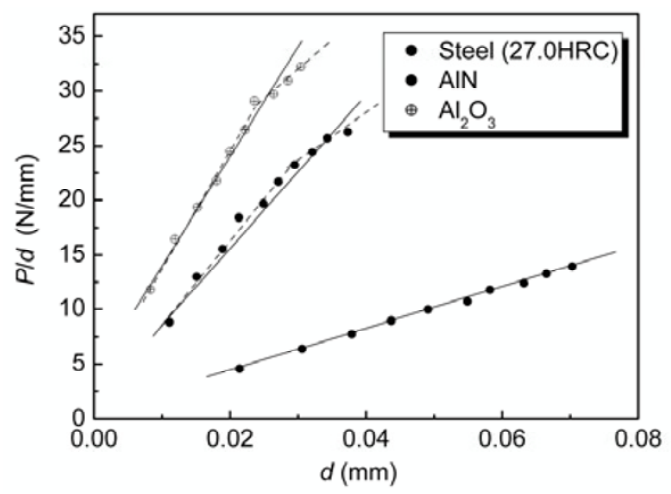

Fig. $3 P / d$ plotted against $d$ for some typical materials. Data from Ref. [11], Knoop indentation

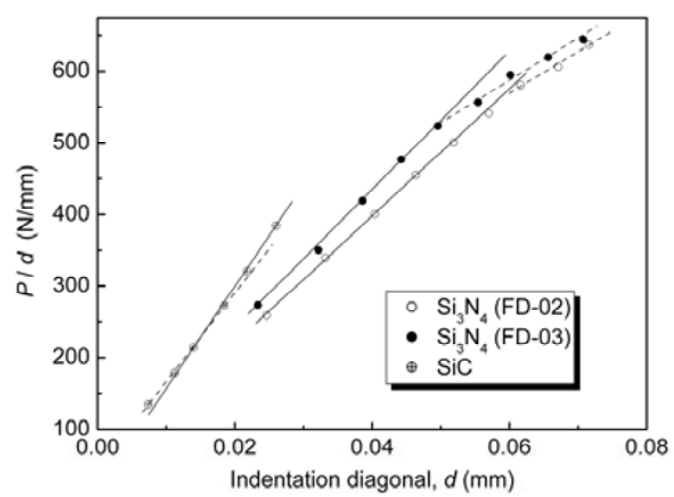

Fig. $4 P / d$ versus $d$ for a sintered SiC (data from Ref. [53]) and two hot-pressed $\mathrm{Si}_{3} \mathrm{~N}_{4}$ ceramics (data from Ref. [52])

the similar experimental phenomena observed in two kinds of typical ceramics, a sintered $\mathrm{SiC}$ [51] and two hot-pressed $\mathrm{Si}_{3} \mathrm{~N}_{4}$ [52] (see Fig. 4). Note that, within examined indentation load range, all three materials exhibited microcracking due to indentation and the crack type transformed from Plmqvist in low load range to half-penny in high load range. Experiments confirmed that, for each material, the load corresponding to the intersection point of the solid line and the dashed line is nearly identical with the critical load for the transformation of crack types. Thus, it was concluded that indentation-induced microcracking plays an important role in the observed ISE. The works of Quinn et al. [5,54], in which the effect of indentation-induced microcracking on the loaddependence of the measured harness was studied extensively, may be considered as a sound support for the analyses of Gong et al. [51,52].

It should be pointed out that the effect of indentation-induced microcracking seems not to be the only source for the change in slope of the $P / d$ vs $d$ 
curve. At least, as shown in Fig. 3, the experimental phenomenon observed for steel cannot be explained by microcracking because it is certain that no microcracking occurs in steel due to its high toughness and low hardness. There is reason to believe that some additional energy-dissipation terms may be omitted in Eq. (4). Therefore, further study should be conducted to try to find these omitted terms in order to refine the energy-balance model.

\subsection{PSR model}

In the early 1990s, Li and Bradt [4] proposed a proportional specimen resistance (PSR) model to provide a new explanation for the observed ISE. This model assumes that, as the load, $P$, is applied to a specimen, $P$ would be partially affected by the material resistance, $P_{\mathrm{r}}$, to plastic flow. To a first approximation, $P_{\mathrm{r}}$ may be considered to be similar to the elastic resistance of a spring with the opposite sign to the applied test load, i.e.,

$$
P_{\mathrm{r}}=a_{1} d
$$

Thus, the effective indentation load and the indentation dimension can be related as:

$$
P_{\text {eff }}=P-P_{\mathrm{r}}=a_{2} d^{2}
$$

Substituting Eq. (7) into Eq. (8) yields

$$
P=a_{1}+a_{2} d
$$

Noting that the form of Eq. (9) is the same as that deduced from the energy-balance consideration, Eq. (4). Therefore, it is undoubted that the PSR model can also describe the indentation data measured in a narrow range of the applied load. One of the advantages of the PSR model compared with the energy-balance consideration is that the constant $\alpha_{1}$ now is related to the elastic properties, making it possible to discuss the effect of elastic deformation on the hardness measurement.

It should be pointed out that the PSR model may be considered as a modified form of the Hays-Kendall approach [29]. When examining the ISE in the Knoop hardness testing of a number of metals, Hays and Kendall [29] advanced a concept that there exists a minimum level of the applied test load, $W$, named the test-specimen resistance, below which permanent deformation due to indentation does not initiate, but only elastic deformation occurs. They introduced an effective indentation load, $P_{\text {eff }}=P-W$, and proposed the following relationship,

$$
P-W=k_{1} h^{2}
$$

where $W$ and $k_{1}$ are constants independent of the test load for a given material.

One important parameter which can be extracted from the analysis of the experimental data according to the Hays-Kendall approach is $W$, the minimum test load below which the material would not exhibit a permanent indentation deformation.

It was generally reported $[4,23,36]$, however, that the $W$-values deduced from the microhardness tests are too large to be acceptable, although this equation may give an excellent description for the indentation data. This may be the main reason for the fact that only a few studies employed the Hays-Kendall approach to analyze the observed ISE. To overcome this obstacle, Li and Bradt [4] considered $W$ as a load-dependent quantity, rather than a constant, yielding Eq. (9).

Several studies have shown that the load-dependent specimen resistance, $P_{\mathrm{r}}$, is a powerful parameter for examining the ISE caused by different mechanisms. For example, Atkinson and Shi experimentally investigated the role of friction between the indenter facets and the test specimen on the Vickers hardness of iron, copper and aluminum [55,56] and found that friction is the main source of the observed ISE. Li et al. [57] analyzed the experimental data of Atkinson and Shi with the PSR model and concluded that the contribution of friction to hardness and the ISE is inversely related to the indentation size, i.e, scaling universally with $(1 / d)$, thereby can be considered properly in the first term on the right side of Eq. (9).

\subsection{The modified PSR model}

Similar to energy-balance model, the PSR model can be used to describe the indentation data only for a narrow indentation load range, see Fig. 3 for example. When examining the indentation size effect in brittle ceramics, as well as some metals, in a relative wide range of the indentation load, a significant nonlinearity was observed in the resultant $P / d$ vs $d$ curve $[32,58]$. To give a reasonable explanation for this experimental phenomenon, Gong et al. [6] presented a phenomenological analysis for the description of the test-specimen resistance, $P_{\mathrm{r}}$.

In the PSR model, the test-specimen resistance was treated approximately as the elastic resistance of a 
spring with the opposite sign to the applied load. Such an approximation seems not to be tenable. In general, the material properties near the surface differ from those in the bulk. Typical examples can be found in materials with a machined or tempered surface, in which the stress state near the surface is rather different to that in the bulk. For the hardness testing of brittle ceramics, the test specimens are generally obtained with a machined and polished surface. The surface machining process, which removes materials mechanically, may introduce both plastic deformation and cracks into the material adjacent to the surface. The elastic/plastic interaction of abrasive grains with the ceramic surface has been considered analogous to a series of closely spaced, single-point indenters. As reviewed by Lawn and co-workers [59,60], a sharp indenter plastically deforms a small volume of material and results in a residual stress effect around the plastic indentation impression. Similar phenomenon would also occur during machining and grinding. Because the plastically deformed volume elements associated with each grinding groove overlap one another, the complete surface would be plastically deformed and in a state of compression [61-63]. Although a quantitative analysis relating the effect of such a plastically deformed surface on the hardness measurements is still lacking, there is reason to believe that, if it is true that the material resistance, $P_{\mathrm{r}}$, of the specimen with a plastically deformed surface can be simulated as the elastic resistance of a spring, such a "spring" must have been in a state of compression, rather than stress-free, before being subjected to indentation. If this were the case, Eq. (7) would be revised as [6]:

$$
P_{\mathrm{r}}=a_{0}+a_{1} d
$$

where $a_{0}$ relates to the residual surface stresses in the test specimen.

Following the PSR model, the effective indentation load, $P-P_{\mathrm{r}}$, and the indentation size, $d$, are related as:

$$
P-P_{\mathrm{r}}=a_{2} d^{2}
$$

Substituting Eq. (11) into Eq. (12) yields:

$$
P=a_{0}+a_{1} d+a_{2} d^{2}
$$

Eq. (12) can be regarded as a revised form of the PSR model. Thus, the physical meanings of the parameters $a_{1}$ and $a_{2}$ in Eq. (13) are the same as those in Eq. (9).

The applicability of Eq. (12) in describing the indentation data has been verified by analyzing a mess of experimental data [64-69]. Here we present a typical example to compare the accuracies of the PSR model and the modified PSR model. Figure 5 (a) shows the measured Vickers hardness, $H_{\mathrm{V}}$, as functions of the applied indentation load, $P$, for five ceramics. Clearly, all the examined materials except mullite show significant ISE. In fact, a slight ISE also exhibit in mullite since analyzing the data for mullite according to the Meyer's law, Eq. (2), yield a Meyer's exponent $n=1.970$ [6]. Each of the data points in Fig. 5 (a) represents an average of measurements from at least five tests and the ISE was observed in each case. The experimental data is then represented in Fig. 5 (b) in a $P / d$ versus $d$ scale (the PSR model) and in Fig. 5 (c) in a $P$ versus $d$ scale (the modified PSR model), respectively. The PSR model is found to be sufficiently

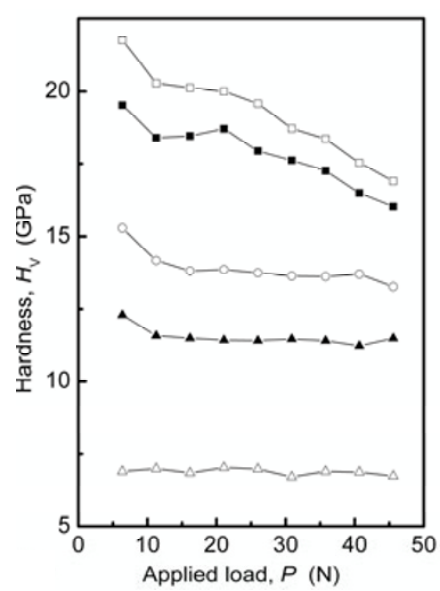

(a)

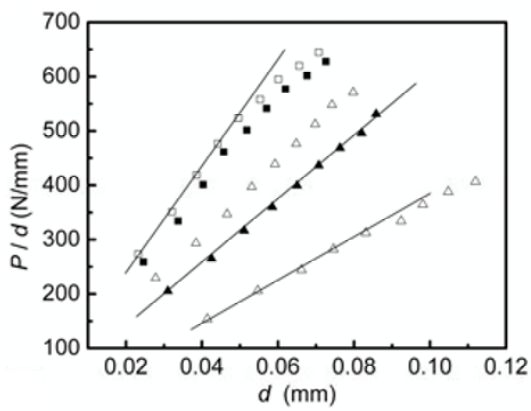

(b)

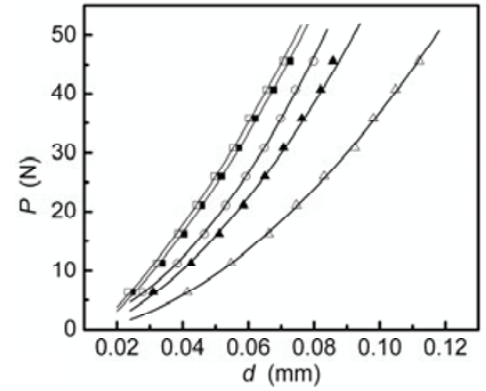

(c)

Fig. 5 (a) Vickers hardness vs applied test load, (b) $P / d$ versus $d$ and (c) $P$ versus $d$ curves for different materials; Data from Ref. [6]: (ロ) FD-02; ( $\square$ ) FD-03; (O) $\mathrm{Al}_{2} \mathrm{O}_{3} ;(\mathbf{\Delta})$ TZP; $(\triangle)$ mullite. 


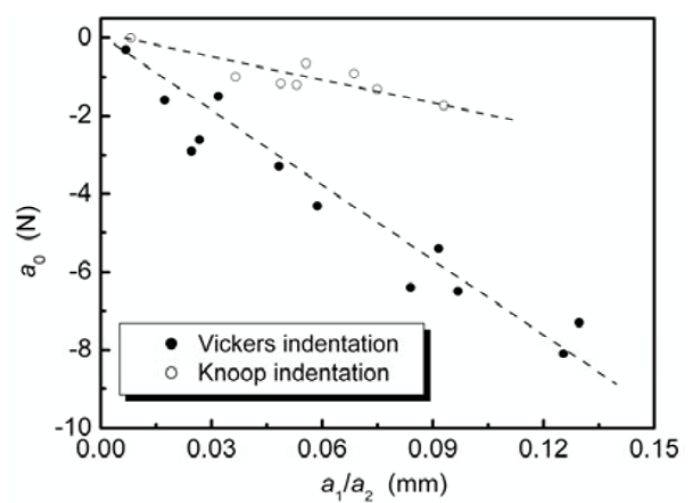

Fig. 6 Relationship between $a_{0}$ and $a_{1} / a_{2}$ for Vickers and Knoop indentation. Data from Refs. [6] and [33], measured with different materials including glass, ceramics, cermets and ceramic composites

suitable for describing the data only for some materials (e.g. TZP), while the modified PSR model is proved to be much powerful for all the examined materials.

\section{Modified PSR model: further comments}

\subsection{Residual stress}

The modified PSR model, Eq. (13), differs in form Eq. (9), the original PSR model only in the $a_{0}$-term.

As discussed by Gong et al. [6], the parameter $a_{0}$ included in Eq. (13) is a measure of the residual surface stress of the test specimen. On the other hand, according to the analysis of $\mathrm{Li}$ and Bradt [4], $a_{1}$ and $a_{2}$ can be related to the elastic and the plastic properties of the test material, respectively. Note that material

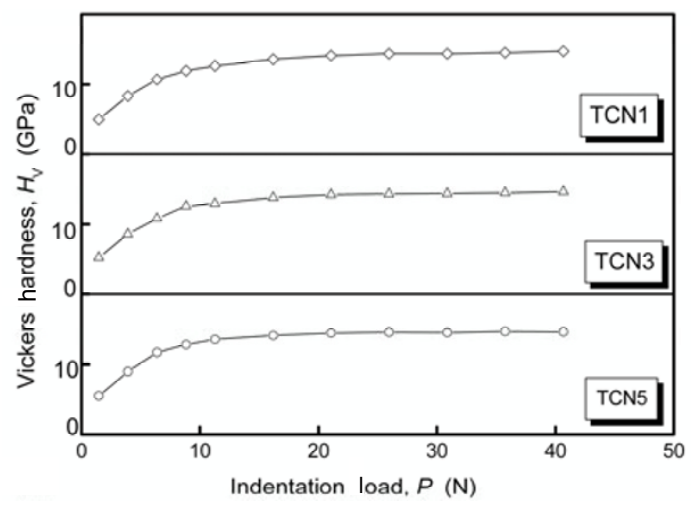

(a) parameter $E / H$ is a measure of the magnitude of the indentation residual stress resulting from the mismatch of the plastic zone and the surrounding elastic matrix [46]. Analogously, the $a_{1} / a_{2}$-value may be treated roughly as a measure of the residual stresses due to machining and polishing. Figure 6 shows the relations between $a_{0}$ and $a_{1} / a_{2}$-value measured with different ceramic materials by Vickers [6] and Knoop [33] indentations, respectively. It is evident that, for a given indenter, there exists a strong correlation between these two parameters, given a sound support for the applicability of the modified PSR model.

In same cases, authors also found that, when analyzing the indentation data measured on a given material according to Eq. (13), the best-fit value of the parameter $a_{0}$ is so small that can be neglected [70-73]. This may be due to the fact that the test samples were subjected to careful surface finishing and, as a result, the residual surface stresses were removed completely [73].

\subsection{Reversed ISE}

It was found that the modified PSR model can also be used to describe the reversed indentation size effect, RISE. RISE, i.e., the fact that the measured hardness increases with increasing indentation size, has been occasionally reported [40,74,75]. An example is shown in Fig. 7 (a), where the apparent hardness was found to increase with increasing applied indentation load for Ti(C,N)-based cermets [40].

Substituting Eq. (9) into Eq. (1) yields

$$
H=k\left(a_{2}+\frac{a_{1}}{d}\right)
$$

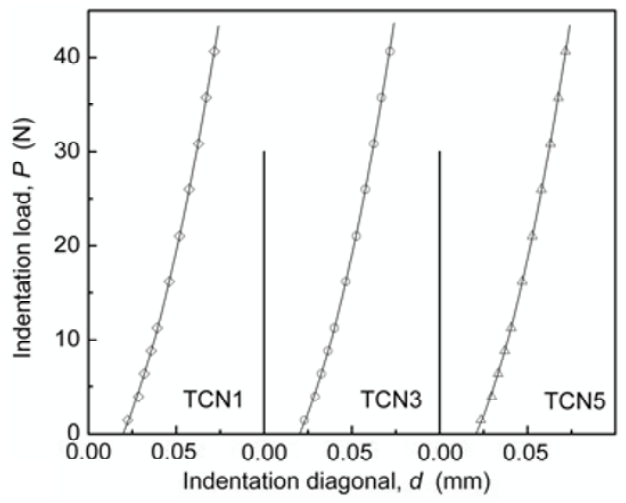

(b)

Fig. 7 Plots of (a) Vickers hardness vs applied test load and (b) indentation size vs the applied test load for a series of Ti(C,N)-based cermets. Data from Ref. [40]. Details about the test materials can be found in Ref. [40] 
Noting that $a_{1}$ is related to the elastic properties of the test material and, thus, should be positive, it can be expected from Eq. (14) that the apparent hardness, $H$, would decrease monotonously with increasing $d$. This is to say that the PSR model or the energy-balance consideration can be used only for the description of the normal ISE, i.e., the phenomenon that the hardness decreases with increasing load, and is unsuitable for describing and analyzing the experimental phenomenon shown in Fig. 7 (a).

However, the modified PSR model is still applicable in this case. As shown in Fig. 7 (b), the best-fit results according to Eq. (13) (the solid lines) are plotted together with the experimental data (symbols), indicating that Eq. (13) can provide an excellent representation of the experimental data.

It is interesting to examine the hardness variation for the considered $\mathrm{Ti}(\mathrm{C}, \mathrm{N})$-based cermets within a much wider range of the applied load. Using the best-fit values of the parameters included in Eq. (13) for the sample TCN1, the apparent hardness numbers were calculated as a function of the indentation size with

$$
H=1.8544\left(\frac{a_{0}+a_{1} d+a_{2} d^{2}}{d^{2}}\right)
$$

The calculated results are shown in Fig. 8 (a) (solid line). Also shown in Fig. 8 (a) are the experimental data measured at different load levels for the same sample. It can be seen that the trend predicted with Eq. (15), solid line in Fig. 8 (a), is in good agreement with the experimental results (symbols).

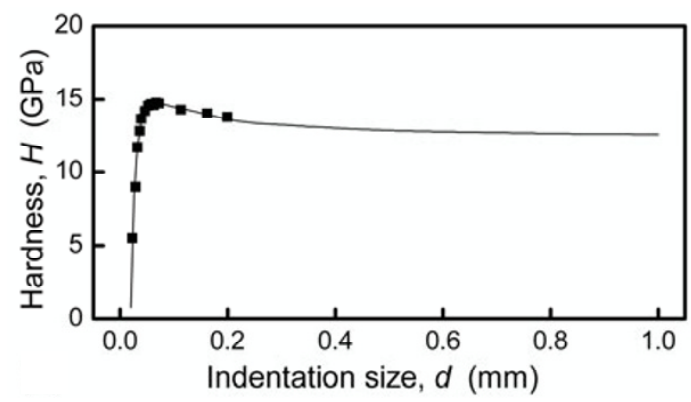

(a)
An interesting feature of Fig. 8 (a) is that, when the indentation size is large enough, a normal indentation size effect will be observed. This seems to say that the RISE may be an experimental phenomenon which can only be observed with a relative lower and narrower range of the applied indentation load. A further support for this statement comes from the analysis of the experimental data reported by Sakai et al. [76]. The original data for the mullite sample M-75 listed in Tables 3 and 4 in Ref. [76] were analyzed according to Eq. (13) and then best-fit values of the parameters $a_{0}$, $a_{1}$ and $a_{2}$ were used to calculate the apparent hardness as a function of test load. The calculated results are now compared with the measured data in Fig. 8 (b). It can be seen that, a RISE is observed for the Vickers hardness testing conducted in the low load range. When the applied load is high enough, both Vickers and Knoop hardnesses exhibit a normal indentation size effect, i.e., the hardness decreases with increasing indentation size.

\subsection{Numerical simulation}

As discussed above, PSR model can describe the indentation data measured within a narrow indentation load range. If the examined indentation load range is broadened, a change in the slope of $P / d$ versus $d$ curve will be observed and then the modified PSR model should be used. The universality of such a phenomenon can be verified by a simple numerical simulation [77]. It has been verified experimentally that the ISE in ceramics can be well described using Meyer's law, Eq. (2), and a correlation coefficient larger than 0.99 can be obtained almost without

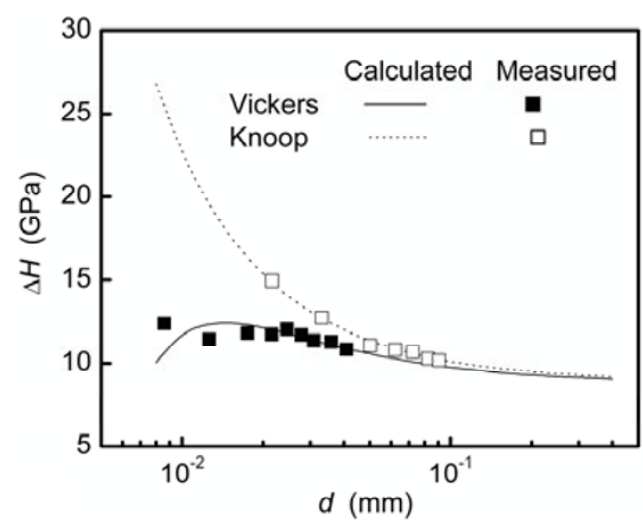

(b)

Fig. 8 Load-dependence of the apparent hardness for (a) Ti(C,N)-based cermet (sample TCN1 in Fig. 7) and (b) mullite ceramic (sample M-75 in Ref. [76]). Symbols represent the experimentally measured data and slid line represents the prediction of Eq. (15) 
exception when analyzing the experimental data according to Eq. (2) by linear regression of the logarithmically transformed data [3,4,6,41-43]. Thus, we can calculate the indentation size, $d$, corresponding to a given applied load, $P$, approximately from Eq. (1) if the exact values of both parameters $n$ and $A$ are known for a given material. In a previous study, the applicabilities of Eqs. (9) and (13) are compared using the "experimental" data calculated from Eq. (2), rather than measured, for three kinds of "imaginary" materials, or three samples, for which the values of parameters $n$ and $A$ are prescribed: $n=1.5$ and $\ln A=$ 8.0 for sample A, $n=1.7$ and $\ln A=8.0$ for sample $\mathrm{B}$, and $n=1.9$ and $\ln A=8.0$ for sample C. In order to obtain a complete understanding of the ISE, the "experimental" data are calculated for a wide range of applied load, 1-20 N. Part of the results are now shown in Fig. 9. It is clear that Eq. (9), the PSR model, does not give an accurate description of the indentation data while Eq. (12), the modified PSR model, is proven sufficiently suitable for studying the indentation size

\section{$x$}

Fig. 9 (Upper) $P / d$ vs $d$ plots and (lower) $P$ vs $d$ plots for the "imaginary" samples. Data calculated according to the Meyer's law with different $n$-values and a fixed $\ln A$ value of 8.0. Figure 3 Relationship between linear shrinkage and drying time of green compacts (four samples) effect in a relatively wide range of indentation load.

\section{General consideration}

In fact, it should be pointed out that the above mentioned progress in the quantitative description of the indentation data, from the Hays-Kendall approach [29], to the PSR model [4] or the energy-balance consideration [30], and finally the modified PSR model [6], may be regarded to be results of the applications of an empirical equation proposed originally by Buckle [78],

$$
P=a_{0}+a_{1} d+a_{2} d^{2}+\cdots+a_{n} d^{n}
$$

where $a_{i}(i=0,1,2, \cdots, n)$ are adjustable constants.

It was usually suggested that the $a_{0}$ term in Eq. (16) corresponds to a load threshold for an indenter to make a permanent indentation and has such a low magnitude that it can be ignored in most situations [5]. Furthermore, a good fit of experimental data was often obtained utilizing only two of the power series terms $[4,30]$. This thus results in an expression used in the energy-balance consideration [30] or the PSR model [4].

Note that Eq. (13), the general form in the modified PSR model differs in form from Eq. (4), the energy-balance consideration, or Eq. (9), the PSR model, only in the $a_{0}$ term, implying that, at least for brittle ceramics, the load threshold $a_{0}$ cannot be ignored. In fact, this can be understood easily by considering the fact that, as mentioned above, the ceramic specimen used for hardness testing usually has a machined and polished surface and the residual surface stresses, resulting from the mismatch between the local plastic deformation and the surrounding elastic matrix, makes the indented surface looks like a pre-stressed, rather than stress-free, "spring". Furthermore, brittle ceramics usually harder than metals and indentation at the same load would yield small plastic impressions in ceramics than in metals, thereby resulting in a much significant effect of residual surface stresses around the indentation impressions, i.e., a larger $a_{0}$ value.

\section{Summary}

In summary, it is sufficient to utilize only the first three 
terms of the power series, Eq. (16), proposed by Buckle [78] to describe the indentation size effect observed in brittle ceramics. If one assumes that the $a_{0}$ term in Eq. (13) has such a low magnitude that it can be ignored, the basic equation used in the energy-balance consideration or the PSR model can be obtained. However, examining the indentation size effect within a relative wide range of the applied load reveals that it seems not to be reasonable to treat the $a_{0}$ term as zero. Therefore, a modified PSR model was proposed and the non-zero $a_{0}$ term was suggested to be related to the residual surface stress resulting from the machining and polishing of the test specimens.

The applicability and the rationality of the modified PSR model were discussed in this paper based on the analysis of some typical experimental results. It was concluded that the modified PSR model can provide a satisfactory description of the experimental data and the best-fit values of the parameters included in Eq. (13), the basic equation deduced from this model, can be explained based on the proposed physical meanings. Furthermore, it was also proved that the modified PSR model may be used to study the reverse indentation size effect.

Open Access This article is distributed under the terms of the Creative Commons Attribution License which permits any use, distribution, and reproduction in any medium, provided the original author(s) and source are credited.

\section{References}

[1] Michels BD, Frischa GH. Microhardness of chalcogenide glasses of the system Se-Ge-As. $J$ Mater Sci 1982, 17: 329-334.

[2] Hirao K, Tomozawa M. Microhardness of $\mathrm{SiO}_{2}$ glass in various environments. $J$ Am Ceram Soc 1987, 70: 497-502.

[3] Clinton DJ, Morrell R. Hardness testing of ceramic materials. Mater Chem Phys 1987, 17: 461-473.

[4] Li H, Bradt RC. The microhardness indentation load/size effect in rutile and cassiterite single crystals. J Mater Sci 1993, 28: 917-926.

[5] Quinn JB, Quinn GD. Indentation brittleness of ceramics: A fresh approach. J Mater Sci 1997, 32: 4331-4346.

[6] Gong JH, Wu JJ, Z.D. Guan. Examination of the indentation size effect in low-load Vickers hardness testing of ceramics. J Europ Ceram Soc 1999, 19:
2625-2631.

[7] Ullner C, Germak A, Le Doussal H, et al. Hardness testing on advanced technical ceramics. J Europ Ceram Soc 2001, 21: 439-451.

[8] Sebastina S, Khadar M. Microhardness indentation size effect studies in $60 \mathrm{~B}_{2} \mathrm{O}_{3}=(40-x) \mathrm{PbO}-x \mathrm{Mcl}_{2}(\mathrm{M}=$ $\mathrm{Pb}, \mathrm{Cd})$ glasses. J Mater Sci 2005, 40: 1655-1659.

[9] Mukhopadhyay NK, Paufler P. Micro- and nanoindentation techniques for mechanical characterization of materials. Inter Mater Rev 2006, 41: 209-245.

[10] Sangwal K. Review: Indentation size effect, indentation cracks and microhardness measurement of brittle crystalline solids - some basic concepts and trends. Cryst Res Technol 2009, 44: 1019-1037.

[11] Young CT, Rhee SK. Evaluation of correction methods for determining load-independent Knoop microhardness. J Test Eval 1978, 6: 221-230.

[12] Mott BW. Micro-Indentation Hardness Testing. London, UK: Butterworths Scientific, 1956.

[13] Bükle IH. Progress in micro-indentation hardness testing. Metall Rev 1959, 4: 49-100.

[14] Blau PJ, Lawn BR, Eds. Microindentation Techniques in Materials Science and Engineering. Philadelphia: American Society for Testing and Materials, 1986.

[15] Brown ARG, Ineson E. Experimental survey of low-load hardness testing instruments. J Iron Steel Institute 1957, 169: 376-388.

[16] Mason W, Johnson PF, Varner JR. Importance of load cell sensitivity in determination of the load dependence of hardness in recording microhardness. J Mater Sci 1991, 26: 6576-6580.

[17] Bückle IH. Use of the hardness test to determine other material properties. In: The Science of Hardness Testing and Its Research Application. Westbook JH, Conrad H, Eds. American Society for Metals, 1973: 453-494.

[18] Tarkanian ML, Neumann JP, Raymond L. Determination of the temperature dependence of $\{100\}$ and $\{112\}$ slip in tungsten from Knoop hardness measurements. In: The Science of Hardness Testing and Its Research Application. Westbook JH, Conrad H, Eds. American Society for Metals, 1973: 187-198.

[19] O'Neill H. The Hardness of Metals and Its Measurement. Cleveland: Sherwood, 1934.

[20] Ma Q, Clarke DR. Size-dependent hardness of silver single-crystals. J Mater Res 1995, 10: 853-863.

[21] Nix WD, Gao HJ. Indentation size effects in crystalline materials: A law of strain gradient plasticity. J Mech. Phys Solids 1998, 46: 411-425. 
[22] Gerberich WW, Tymiak NI, Grunlan JC, et al. Interpretations of indentation size effects. $J$ Appl Mech Trans ASME 2002, 69: S433-442.

[23] Sangwal K, Surowska B, Blaziak P. Analysis of the indentation size effect in the microhardness measurement of some cobalt-based alloys. Mater Chem Phys 2003, 77: 511-520.

[24] Sahin O, Uzun O, Kolemen U, et al. Indentation size effect and microhardness study of beta-Sn single crystals. Chin Phys Lett 2005, 22: 3137-3140.

[25] Kolemen U. Analysis of ISE in microhardness measurements of bulk $\mathrm{MgB}_{2}$ superconductors using different models. J Alloys Comp 2006, 425: 429-435.

[26] Anandakumar VM, Khadar MA. Microhardness studies of nanocrystalline lead molybdate. Mater Sci Eng A 2009, 519: 141-146.

[27] Terzioglu C. Investigation of some physical properties of Gd added Bi-2223 superconductors. $J$ Alloys Comp 2011, 509: 87-93.

[28] Meyer E. Investigations on hardness testing and hardness. VDI Zeitschriff 1908, 52: 2077-2078.

[29] Hays C, Kendall EG. An analysis of Knoop microhardness. Metall 1973, 6: 275-282.

[30] Fröhlich F, Grau P, Grellmann W. Performance and analysis of recording microhardness tests. Phys Status Solidi 1977, 42: 79-89.

[31] Gong JH, Si WJ, Guan ZD. Effect of load-dependence of hardness on indentation toughness determination for soda-lime glass. $J$ Non-Cryst Solids 2001, 282: 325-328.

[32] Gong JH, Wu JJ, Guan ZD. Load dependence of the apparent hardness of silicon nitride ceramics in a wider range of loads. Mater Lett 1998, 35: 58-61.

[33] Gong JH, Guan ZD. Load dependence of low-load Knoop hardness in ceramics: a modified PSR model. Mater Lett 2001, 47: 140-144.

[34] Gong JH. Comment on "measurement of hardness on traditional ceramics". J Europ Ceram Soc 2003, 23: 1769-1772.

[35] Gong JH, Pan XT, Miao HZ, et al. Effect of metallic binder content on the microhardness of TiCN-based cermets. Mater Sci Eng A 2003, 359: 391-395.

[36] Gong JH, Zhao Z, Guan ZD, et al. Load-dependence of Knoop hardness of $\mathrm{Al}_{2} \mathrm{O}_{3}$-TiC composites. $J$ Europ Ceram Soc 2000, 20: 1895-1900.

[37] Gong JH, Miao HZ, Hu BJ. Compositional dependence of hardness of $(\mathrm{Ce}, \mathrm{Y})-\mathrm{TZP} / \mathrm{Al}_{2} \mathrm{O}_{3}$ composites. Mater Sci Eng A 2004, 372: 207-212.

[38] Peng ZJ, Gong JH, Miao HZ. On the description of indentation size effect in hardness testing for ceramics: analysis of the nanoindentation data. $J$ Europ Ceram Soc 2004, 24: 2193-2201.
[39] Dey A, Mukhopadhyay AK, Gangadharan S, et al. Nanoindentation study of microplasma sprayed hydroxyapatite coating. Ceram Int 2009, 35: 2295-2304.

[40] Gong JH, Miao HZ, Zhao Z, et al. Load-dependence of the measured hardness of $\mathrm{Ti}(\mathrm{C}, \mathrm{N})$-based cermets. Mater Sci Eng A 2001, 303: 179-186.

[41] Charkraborty D, Mukerji J. Characterization of silicon nitride single crystals and polycrystalline reaction sintered silicon nitride by microhardness measurements. J Mater Sci 1980, 15: 3051-3056.

[42] Babini GN, Bellosi A, Galassi C. Characterization of hot-pressed silicon nitride-based materials by microhardness measurements. J Mater Sci 1987, 22: 1687-1693.

[43] Sargent PM, Page TF. The influence on the microhardness of ceramic materials. Proc Brit Ceram Soc 1978, 26: 209-224.

[44] Li H, Bradt RC. Knoop microhardness anisotropy of single crystal cassiterite $\left(\mathrm{SnO}_{2}\right)$. J Am Ceram Soc 1991, 74: 1053-1060.

[45] Gong JH, Guan ZD. Energy-balance relationship in Knoop hardness test for ceramics. J Chin Ceram Soc 1995, 23: 308-313.

[46] Lawn BR, Evans AG, Marshall DB. Elastic/plastic indentation damage in ceramics: The median/radial crack system. J Am Ceram Soc 1980, 63: 574-581.

[47] Gong JH, Yuan QM. Indentation size effect for Knoop hardness testing. J Tianjin Univ 1996, 29: 727-731.

[48] Gong JH, Li LX. Indentation hardness of mullite based ceramics. J Inorg Mater 1996, 11: 375-380.

[49] Mukhopadhyay NK. Analysis of microhardness data using the normalized power law equation and energy balance model. J Mater Sci 2005, 40: 241-244.

[50] Liu Q, Yao YX, Zhou L. Theoretical analysis of indentation size effect. J Test Meas Technol 2009, 23: 1-6.

[51] Gong JH. On the energy balance model for conventional Vickers microhardness testing of brittle ceramics. J Mater Sci Lett 2000, 19: 515-517.

[52] Gong JH, Guan ZD. Effect of microcracking on the energy-balance relationship for hardness testing of ceramics. Mater Lett 2001, 49: 180-184.

[53] Li Z, Ghosh A, Kobayashi AS, et al. Indentation fracture toughness of sintered silicon carbide in the Palmqvist crack regime. J Am Ceram Soc 1989, 72: 904-911.

[54] Quinn GD, Green P, Xu L. Cracking and the indentation size effect for Knoop hardness of glasses. J Am Ceram Soc 2003, 86: 441-448.

[55] Atkinson M, Shi H. Friction effect in low load 
hardness testing of iron. Mater Sci Technol 1989, 5: 613-614.

[56] Shi H, Atkinson M. A friction effect in low-load hardness testing of copper and aluminum. J Mater Sci 1990, 25: 2111-2114.

[57] Li H, Ghost A, Han YH, et al. The friction component of the indentation size effect in low load microhardness testing. J Mater Res 1993, 8: 1028-1032.

[58] Gong JH, Wu JJ, Guan ZD. Description of the indentation size effect in hot-pressed silicon-nitride-based ceramics. $J$ Mater Sci Lett 1998, 17: 473-475.

[59] Lawn BR, Wilshaw TR. Indentation fracture: Principles and applications. J Mater Sci 1975, 10: 1049-1081.

[60] Marshall DB, Lawn BR. Residual stress effects in sharp contact cracking: Part 1 Indentation fracture mechanics. J Mater Sci 1979, 14: 2001-2012.

[61] Johnsonwalls D, Evans AG, Marshall DB, et al. Residual stresses in machined ceramic surfaces. $J \mathrm{Am}$ Ceram Soc 1986, 69: 44-47.

[62] Li K, Liao TW. Surface/subsurface damage and the fracture strength of ground ceramics. $J$ Mater Process Technol 1996, 57: 207-220.

[63] Wu H, Roberts SG, Berby B. Residual stress and subsurface damage in machined alumina and alumina/silicon carbide nanocomposite ceramics. Acta Mater 2001, 49: 507-517.

[64] Xie ZH, Hoffman M, Cheng YB. Microstructural tailoring and characterization fo a calcium $\alpha \mathrm{SiAlON}$ composition. J Am Ceram Soc 2002, 85: 812-818.

[65] Kolemen U, Uzun O, Yilmazlar M, et al. Hardness and microstructural analysis of $\mathrm{Bi}_{1.6} \mathrm{~Pb}_{0.4} \mathrm{Sr}_{2} \mathrm{Ca}_{2}-x \mathrm{Sm}_{x} \mathrm{Cu}_{3} \mathrm{O}_{y} \quad$ polycrystalline superconductors. J Alloys Comp 2006, 415: 300-306.

[66] Sidjanin L, Rajnovic D, Ranogajec J, et al. Measurement of Vickers hardness on ceramic floor tiles. J Europ Ceram Soc 2007, 27: 1767-1773.

[67] Wang K, Russel C, Liu CS. Preparation, mechanical properties and corrosion behaviors of oriented
$\mathrm{Ca}\left(\mathrm{PO}_{3}\right)_{2}$ glass-ceramics. Mater Chem Phys 2008, 111: 106-113.

[68] Sahin O, Uzun O, Sopicka-Lizer M, et al. Dynamic hardness and elastic modulus calculation of porous SiAlON ceramics using depth-sensing indentation technique. J Europ Ceram Soc 2008, 28: 1235-1242.

[69] Filetin T, Solic S, Zmak I. The indentation size effect on the micro-hardness of sea mollusk shell structures. Mater Test 2011, 53: 48-53.

[70] Chicot D, Roudet F, Soom A, et al. Interpretation of instrumented hardness measurements on stainless steel with different surface preparations. Surf Eng 2007, 23: 32-39.

[71] Sidjanin L, Ranogajec J, Rajnovic D, et al. Influence of firing temperature on mechanical properties on roofing tiles. Mater Design 2007, 28: 941-947.

[72] Nursoy M, Yilmazlar M, Terzioglu C, et al. Transport, microstructure and mechanical properties of $\mathrm{Au}$ diffusion-doped Bi-2223 superconductors. J Alloys Comp 2008, 459: 399-406.

[73] Rios CT, Coelho AA, Batista WW, et al. ISE and fracture toughness evaluation by Vickers hardness testing of an $\mathrm{Al}_{3} \mathrm{Nb}-\mathrm{Nb}_{2} \mathrm{Al}-\mathrm{AlNbNi}$ in situ composite. J Alloys Comp 2009, 472: 65-70.

[74] Feltham P, Banerjee R. Theory and application of microindentation in studies of glide and cracking in single crystals of elemental and compound semiconductors. J Mater Sci 1992, 27: 1626-1632.

[75] Li H, Bradt RC. The effect of indentation-induced cracking on the apparent microhardness. J Mater Sci 1996, 31: 1065-1070.

[76] Sakai T, Ghosh A, Bradt RC. The indentation fracture resistance of self-reinforced mullites. In: Fracture Mechanics of Ceramics, Vol. 10. Bradt RC, Hasselman DPH, Munz D, et al, Eds. New York: Plenum, 1992: 119-133.

[77] Gong JH, Wu JJ, Guan ZD. Analysis of the indentation size effect on the apparent hardness for ceramics. Mater Lett 1999, 38: 197-201.

[78] Bückle H. Mikrohärteprüfung. Stuttgart, Germany: Berliner Union Verlag, 1965. 